\title{
OPTIMALISASI RinfoCal PADA GO+ SEBAGAI REMINDER PEMBAYARAN PERKULIAHAN PADA PERGURUAN TINGGI RAHARJA
}

\author{
Abdul Hamid Arribathi ${ }^{1}$ \\ Qurotul Aini ${ }^{2}$ \\ Silvia Permatasari ${ }^{3}$

\begin{abstract}
Dosen STMIK Raharja Tangerang ${ }^{1,2}$, Mahasiswa STMIK Raharja Tangerang ${ }^{3}$
Jl. Jenderal Sudirman No.40 Modernland Cikokol, Tangerang ${ }^{1,2,3}$
\end{abstract} \\ e-mail: abdulhamid@ raharja.info ${ }^{1}, \underline{\text { aini@ }}$ raharja.info $^{2},{\underline{\text { silvia.permatasari@ } \text { raharja.info }^{3}}}^{3}$
}

\begin{abstract}
ABSTRAK
Pemanfaatan teknologi pada perguruan tinggi banyak digunakan dalam metode penerapan metode perkuliahan maupun bagi kelancaran kebutuhan pembayaran biaya kuliah. Di Perguruan Tinggi Raharja terdapat sistem transaksi pembayaran biaya perkuliahan yaitu Go+, dimana hal tersebut tidak hanya mempermudah mahasiswa tetapi juga manajemen. Namun dalam prosesnya masih terjadi $I$ (satu) kendala yang sangat mempersulit mahasiswa juga manajemen dalam mendapatkan notifikasi pengingat pembayaran perkuliahan sebelum tanggal jatuh tempo. Sehingga perlu adanya pengembangan menggunakan Rinfo Transformations, dengan memanfaatkan fitur RinfoCal (Rinfo Calender) yang dapat secara otomatis memberikan notifikasi yang dibutuhkan bagi Pribadi Raharja. Penelitian ini menggunakan metode Prototype. Dimana terdapat 4 (empat) literature review sebagai referensi dari penelitian sebelumnya, 4 (empat) keuntungan yang didapat dari sistem. Dari pemecahan masalah yang diutarakan ini, diharapkan dapat mempermudah manajemen dalam menyebarkan informasi kepada mahasiswa, serta mahasiswa dapat secara otomatis menerima pengingat tersebut melalui device masing-masing.
\end{abstract}

Kata kunci: $G O+$, Pembayaran, Rinfocal.

\begin{abstract}
Utilization of technology in universities is widely used in the method of application of lecturing methods as well as for the smoothness of tuition fee payment needs. In Higher Education Raharja there is a payment transaction system lecture fee is $G o+$, where it is not only easier for students but also management. However, in the process there is still 1 (one) obstacle which is very difficult for students and management in getting notification of reminder of tuition payment before due date. So the need to develop using Rinfo Transformations, by utilizing the feature RinfoCal (Rinfo Calendar) which can automatically provide the required notification for Personal Raharja. This research uses Prototype method. Where there are 4 (four) literature review as a reference from previous research, 4 (four) advantages gained from the system. From the solution of this expressed problem, it is expected to facilitate the management in disseminating information to students, and students can automatically receive the reminder through their respective devices.
\end{abstract}

Keyword: $G O+$, Pembayaran, Rinfocal.

\section{PENDAHULUAN}

Perkembang teknologi di dalam perguruan tinggi raharja semakin hari semakin pesat. Salah satunya ialah informasi tentang pembayaran perkuliahan di sebuah Perguruan Tinggi Raharja. Sebuah perguruan tinggi perlu memiliki sistem pembayaran perkuliahan yang dapat 
mengingatkan (reminder) mahasiswa untuk melihat tagihan biaya perkuliahan dan mengingatkan tanggal akhir batas pembayaran perkuliahan secara otomatis

Green orchestra + atau biasa dikenal dengan GO+ ialah sebuah sistem berbasis online yang dirancang perguruan tinggi raharja untuk memberikan informasi mengenai total tagihan biaya perkuliahan, dan batas pembayaran perkuliahan. Di dalam $\mathrm{GO}+$ sendiri terdapat informasi berupa RBK, dan RBR. RBR ialah rincian tagihan biaya kuliah berupa biaya registrasi atau BPP, dan RBK ialah tagihan biaya kuliah berupa biaya sks, BPP, Ukm, Tunggakan Sks, Transfer, Konversi, Bimbingan Is.[1]

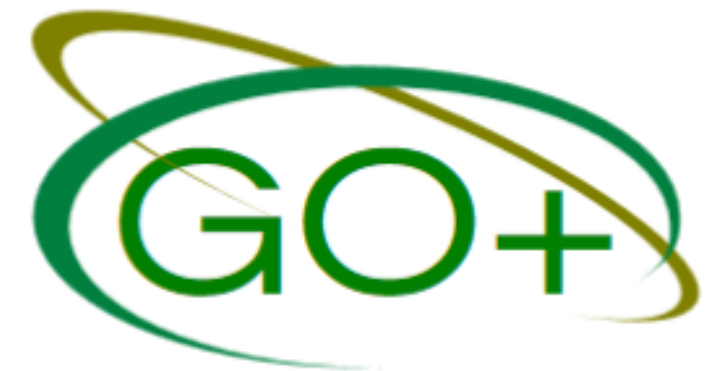

Gambar 1. Logo GO+

Sumber : Why GO+ (2016 : iran.ilearning.me)

Rinfocal merupakan sebuah kalender yang bersifat online dimana RinfoCal merupakan tools yang terdapat didalam rinfo yang memiliki fungsi sebagai pengingat (reminder)kegiatan kampus, tugas, serta pembayaran perkuliahan yang notifikasinya akan dikirimkan melalui rinfo. Rinfo adalah sebuah email yang dibuat oleh perguruan tinggi raharja yang dikhususkan untuk mahasiswa perguruan tinggi raharja yang berfungsi untuk mengerjakan tugas, yang didalamnya terdapat RinfoSites, RinfoDocs, RinfoGroup, RinfoDrive, RinfoH, dan RinfoCal.[3]

Salah satu fungsi Rinfo ialah memberikan informasi yang disampaikan melalui sebuah notifikasi email yang digunakan sebagai media komunikasi antara mahasiswa dengan dosen, atau antar sesama dosen. Notifikasi yang diberikan berkaitan dengan kegiatan perkuliahan yang sedang berjalan, seperti menyampaikan informasi tentang tugas yang diberikan kepada mahasiswa, nilai yang diberikan dosen kepada mahasiswa setelah selesai mengerjakan tugas, dan memberitahukan mahasiswa bagaimana cara mendapatkan informasi tentang kegiatan akademik yang sedang berjalan di Perguruan Tinggi Raharja dengan efektif dimanapun.[4]

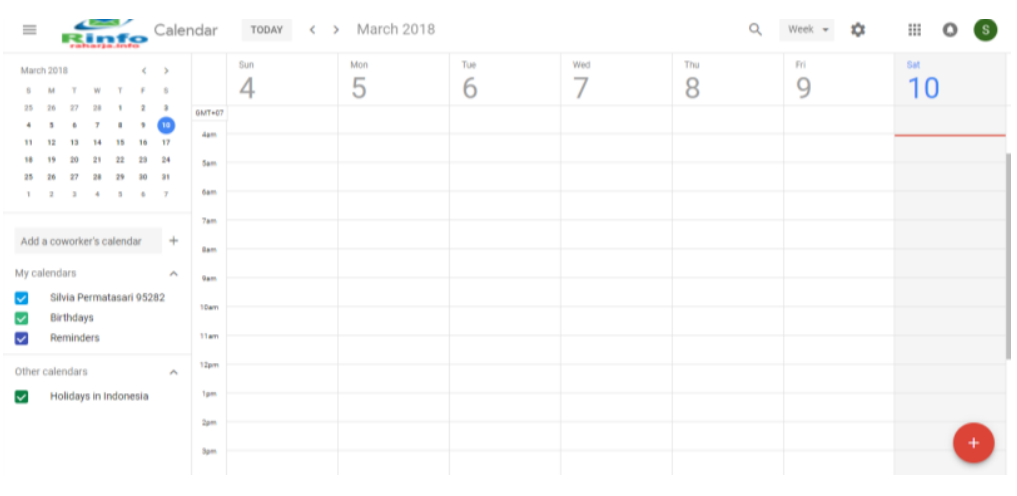

Gambar 2. tampilan utama RinfoCal

Selain itu Rinfocal dapat berfungsi fungsi untuk, memberikan informasi kepada 
pribadi raharja memberikan infromasi kepada mahasiswa tmengenai batas akhir pembayaran perkuliahan. Sehingga pribadi raharja tidak perlu ke administrasi untuk menanyakan total tagihan biaya pembayaran perkuliahan. [5]

Reminder ialah pesan yang mampu menolong seseorang untuk mengingatkan sesuatu hal, misalnya pertemuan janji, mengingatkan deadline tugas, mengingatkan suatu kegiatan yang di selenggarakan oleh perguruan tinggi, sampai mengingatkan batas akhir pembayaran perkuliahan. Reminder sendiri akan lebih bermanfaat jika informasi kontekstual digunakan untuk menyajikan suatu informasi yang akurat. [6].

Pembayaran ialah sesuatu yang biasa dilakukan setelah membeli jasa ataupun membeli suatu barang tertentu, sehingga pembayaran merupakan hal terpenting supaya perekonomian terus berjalan. Pembayaran biasanya dilakukan pada bagian kasir ditiap tempatnya dan saat melakukan pembayaran banyak sekali antrian.[7].

Penggunaan RinfoCal pada GO+ diharapkan dapat mengingatkan pribadi raharja mengenai informasi pembayaran perkuliahan kapanpun dan dimanapun melalui notifikasi email Rinfo sehingga pribadi raharja tidak perlu pergi ke bagian kasir untuk melakukan pengecekan.

\section{PERMASALAHAN}

Didalam perkuliahan banyak sekali mahasiswa yang masih mendatangi bagian administrasi atau kasir untuk melakukan pengecekan terhadap batas akhir pembayaran perkuliahan serta mengecek berapa total pembayaran perkuliahan, dimana hal tersebut sangat tidak efektif karna membuang-buang waktu..

Terdapat 1 (satu) permasalahan sehingga kurang efektifnya proses transaksi pembayaran biaya perkuliahan. Dimana banyak mahasiswa yang masih mendatangi bagian administrasi atau kasir untuk melakukan pengecekan terhadap tanggal batas akhir pembayaran perkuliahan serta mengecek berapa total tagihan pembayaran perkuliahan. Tentunya hal itu tidak sejalan dengan Perguruan Tinggi Raharja yang berada dalam bidang IT. Sehingga diperlukan suatu fitur pengingat (reminder) yang untuk membantu manajemen serta mahasiswa, dalam sisi manajemen untuk bisa mengingatkan mahasiswa terhadap tagihan pembayaran perkuliahan agar tidak melewati batas jatuh tempo.

Yang saat ini berjalan di Perguruan Tinggi Raharja yaitu menggunakan media konvensional spanduk untuk memberitahukan mahasiswa tentang jatuh tempo pembayaran perkuliahan yang belum tentu seluruh mahasiswa melihatnya karena letak pemasangan yang kurang strategis. Banyak mahasiswa kurang lebih 2.500 tidak semuanya mau menghampiri papan majalah dinding (mading) untuk melihat informasi pamflet. Karena tampilan yang tidak menarik, kurang terawat, juga banyak informasi yang sudah tidak update. Hal tersebut yang mengakibatkan pikiran mahasiswa menjadi tidak ada rasa tertarik untuk melihatnya. Dan juga dimintanya bantuan kepada dosen untuk disampaikan di kelas saat proses pembelajaran berlangsung dengan cara menyelipkan selembar kertas di dalam ISAP, lagi-lagi hal itu tidak dapat berjalan seperti yang diharapkan. Pastinya telah banyak cara dilakukan, namun tetap saja tercatat para mahasiswa banyak yang telat dalam melakukan pembayaran perkuliahan. Dan yang selalu dilakukan juga adalah dengan cara mengirimkan informasi tagihan pembayaran perkuliahan di dalam amplop coklat melalui media POS, kirim surat menggunakan perangko. Seperti yang diketahui bersama bahwa amplop tersebut akan sampai dengan baik sesuai alamat, namun pihak mahasiswa atau keluarga yang bersangkutan menerimanya selalu telat

Lalu apa hubungannya antara Rinfocal dengan GO+ sebagai reminder pembayaran perkuliahan? Pertama, pihak kampus selalu menggunakan spanduk untuk memberitahukan mahasiswa tentang jatuh tempo pembayaran perkuliahan, padahal di zaman teknologi seperti 
sekarang informasi bisa dikirimkan secara online. Selain itu setiap mahasiswa di perguruan tinggi raharja pastinya selalu mengecek berapa total tagihan biaya kuliah serta batas akhir pembayaran secara online ataupun menanyakan langsung ke kasir, terkadang ada beberapa mahasiswa yang lupa melihat berapa total tagihan biaya perkuliahan, sehingga tidak mengetahui berapa total tagihan biaya perkuliahannya. Kedua, mahasiswa terkadang lupa tanggal jatuh tempo pembayarannya. Sehingga harus bertanya ke bagian kasir.

Dari permasalahan yang telah dibahas dapat disimpulkan bahwa banyaknya mahasiswa yang melakukan pengecekan pembayaran sudah seharusnya sebuah perguruan tinggi memiliki sistem yang bisa memberikan informasi berupa notifikasi email kepada mahasiswa mengenai batas waktu pembayaran.

Telatnya pembayaran biaya perkuliahan oleh mahasiswa pasti sangat menganggu manajemen dalam proses keuangan karena tidak dapat berjalan lancar dalam proses pembiayaan operasional kampus. Untuk itu dari permasalahan yang telah dibahas dapat disimpulkan bahwa informasi berupa notifikasi email atau pop up di device masing-masing kepada mahasiswa mengenai batas waktu pembayaran sangat dibutuhkan. Karena di era digital saat ini, terkoneksinya seluruh Pribadi Raharja dengan Rinfo akan memberikan manfaat yang sangat signifikan, pengingat yang dibutuhkan akan diterima tepat sasaran.

\section{LITERATURE REVIEW}

Banyak penelitian sebelumnya yang telah dilakukan berkaitan dengan Rinfocal dan GO+. Untuk mengembangkan penggunaan Rinfocal pada $\mathrm{GO}+$ sebagai pengingat sistem pembayaran perkuliahan, maka perlu dilakukan studi pustaka untuk menerapkan metode penelitian yang akan dilakukan. Berikut ini adalah literature review yang dilakukan dalam penilitian ini:

1) Penelitian ini sebelumnya telah dilakukan pada tahun 2014 dengan tiga penulis yang terdiri dari Rahardja, Untung, Khanna Tiara, and Ray Indra Taufik Wijaya. "Penerapan Rinfo Sebagai Media Pendukung Untuk Proses Pembelajaran Pada Perguruan Tinggi Raharja." Jurnal CCIT8, no. 1 (2014). penelitian tersebut membahas mengenai penggunaan email rinfo dalam kegiatan pembelajaran dengan menggunakan sistem pembelajaran i-learning dimana mahasiswa dapat dengan mudah mengakses materi pembelajaran dimanapun dan kapanpun, serta menyediakan wadah dalam bentuk rinfo atau email yang dibuat oleh perguruan tinggi raharja untuk mengerjakan tugas. Namun penelitian ini masih memiliki kekurangan yaitu untuk mengakses sistem ini harus terhubung dengan jaringan internet.

2) Penelitian sebelumnya juga pernah dilakukan pada tahun 2015 oleh Handayani, Indri, Qurotul Aini, and Yessy Oktavyanti. "Penggunaan RinfoCal Sebagai Aplikasi Pengingat (Reminder) Kegiatan Akademik Pada Perguruan Tinggi." CCIT Journal 9, no. 1 (2015): 13-26. membahas tentang penggunaan kalender sebagai pengingat kegiatan akademik di perguruan tinggi melalui aplikasi rinfocal yang merupakan tools yang ada di rinfo, untuk membantu mahasiswa dalam mengingatkan kegiatan akademik melalui notifikasi rinfo (email) agar tidak ada kegiatan kampus yang terlewatkan. Penelitian tersebut menggunakan metode studi kasus disalah satu perguruan tinggi. Akan tetapi penelitian ini memiliki kekurangan seperti belum banyak mahasiswa yang mengetahui fungsi dari Rinfo calendar sendiri, mahasiswa masih mengira bahwa Rinfo calendar hanya sebuah kalender biasa saja.

3)Azizah, Nur, and Andri Ansyah. "PERANCANGAN SISTEM INFORMASI MONITORING ANTRIAN PEMBAYARAN KULIAH PADA LKM PERGURUAN 
TINGGI RAHARJA." CCIT Journal 9, no. 1 (2015): 60-70.

bahasa pemrograman ini menggunakan bahasa Hypertext Prepocessor atau biasa disebut PHP, database MySQL menggunakan metode penelitian prototype. Penelitian ini bertujuan untuk merancang dan membuat sebuah aplikasi yang dapat membantu mahasiswa untuk lebih nyaman saat menunggu antrian tanpa harus berdiri. Penelitian ini menghasilkan sistem monitoring antrian yang diharapkan dapat mengawasi banyaknya mahasiswa yang melakukan antrian sehingga pada saat mengantri mahasiswa tidak perlu lagi berdiri di depan LKM. Namun sistem ini masih memiliki sedikit kekurangan yakni massih harus menunggu panggilan sesuai dengan nomor urut yang telah dijadwalkan

4) Yusup, Muhamad, Untung Rahardja, and Susan Oktaviani. "GO+ Dalam Menunjang Int+ Untuk Pengelolaan Data Cmb Pada Perguruan Tinggi." CCIT Journal 8, no. 1 (2014): 65-82.Membahas mengenai pengolahan data-data calon mahasiswa baru. Metode prototype digunakan sebagai metode penelitian ini. Penelitian ini mempunyai 3 tujuan, yaitu yang pertama penelitian ini bertujuan agar kegiatan promosi kampus kepada Calon Mahasiswa Baru meningkat. Tujuan yang kedua ialah untuk memberikan pelayanan terbaik dalam mengelola data Calon Mahasiswa Baru. Dan tujuan yang terakhir adalah untuk meningkatkan kualitas pelayanan staf Marketing.Dan kekurangannya pada penelitian ini ialah masih menggunakan web sehingga mahasiswa masih harus melakukan login berkali-kali[8]

5) Penelitian tahun 2016 yang Tiara, Khanna, and Tuti Nurhaeni. "Penerapan Viewboard GO+ Berbasis Yii Sebagai Media Monitoring Pembayaran Mahasiswa." Technomedia Journal 1, no. 1 (2016): 65-77. Membahas tentang penerapan viewboard GO+ sebagai media peenerapan pembayarann mahasiswa dengan tujuan memudahkan mahasiswa medapatkan informasi secara mudah, menggunakan metode penelitian berbasis Web. Pada sistem Viewboard GO+ ini masi dalam proses tahap awal saja akibatnya informasi yang dihasilkan sistem ini masih kurang.

Dari ke-5 literatur review diatas, telah banyak peneliti yang menggunakan sistem pengecekan pembayaran perkuliahan secara online. Akan tetapi dapat disimpulkan bahwa belum adanya penelitian yang menerapkan sistem reminder pembayaran perkuliahan yang informasi rincian biaya perkuliahannya akan dikirimkan melalui email kepada seluruh mahasiswa.

\section{PEMECAHAN MASALAH}

Pemecahan masalah ialah proses dimana sebuah situasi diamati dan jika ditemukan masalah maka perlu adanya penyelesaian dengan beberapa cara, yaitu; masalah harus ditentukan, mengurangi masalah atau menghilangkan masalah tersebut atau mencegah

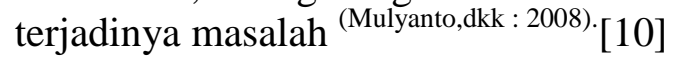

Untuk mengatasi masalah yang telah dibahas sebelumnya, maka diperlukan pengembangan sistem yang ada pada GO+. Salah satunya ialah memanfaatkan tools yang terdapat dalam Rinfo yaitu Rinfocal untuk mengirimkan informasi tagihan biaya kuliah serta batas akhir pembayaran perkuliahan yang terdapat di dalam GO+ melalui notifikasi email Rinfo.

Dari rumusan permasalahan yang telah dibahas sebelumnya dapat kita simpulkan yaitu dengan adanya Rinfocall memudahkan mahasiswa untuk mengingatkan batas waktu pembayaran dimanapun dan kapanpun. Pada pemecahan masalah ini Rinfocal sebagai pengingat (reminder) pada GO+ menggunakan metode studi kasus dan mind mapping seperti dibawah ini: 
1. Tahapan yang digunakan dalam penyusunan penelitian ini dapat dilihat pada gambar dibawah ini

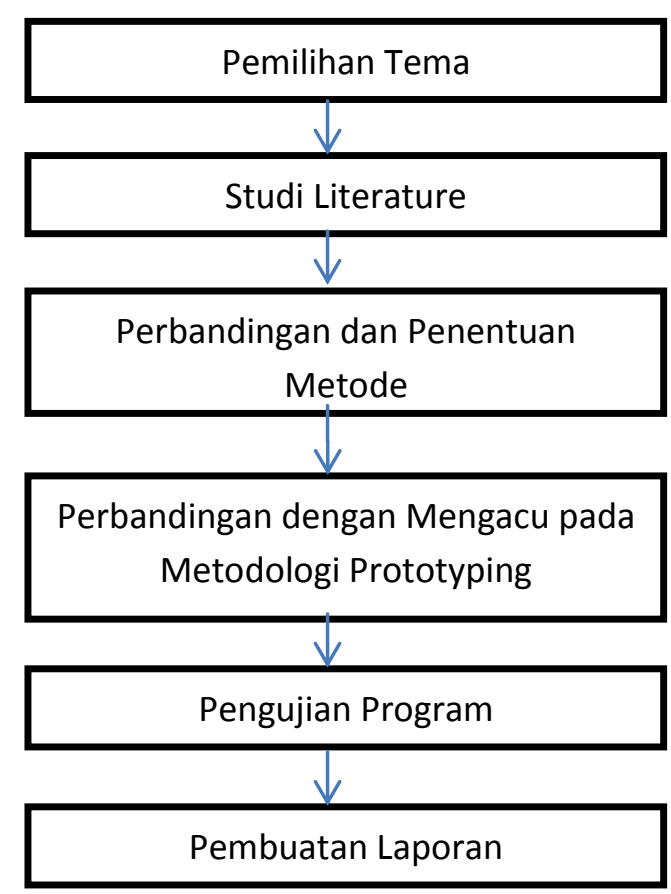

Gambar 3. Tahapan Penelitian

\section{Keterangan:}

a) Mencari Permasalahan yang terjadi, lalu menentukan Tema yang akan diambil yaitu $\mathrm{GO}+$

b) Studi literature, yang dilakukan adalah mencari refrensi sistem GO+, membaca, dan memahami berbagai sumber yang ada seperti jurnal dan buku

c) Membandingkan metode yang sudah digunakan, membandingkan metode sistem notifikasi email otomatis guna mendapatkan metode yang tepat untuk diimplementasikan pada proses pembuatan program

d) Penggunaan metode perancangan sistem yang tepat serta disesuaikan dengan permasalahan dan disesuaikan dengan permasalahan dan program yang diciptakan. Metodologi yang digunakan dalam perancangan program ini adalah metode prototyping

e) Pengujian program, tahapan yang dilakukan untuk validitas dan reabilitas pada program yang dibuat

f) Menulis laporan dalam bentuk dokumen online

2. Mind mapping

Mind Mapping yaitu sebuah langkah yang efektif serta efisien yang bertujuan utnuk memasukan data, mengeluarkan data dan menyimpan data dari atau ke otak. Cara kerja sistem ini ialah bekerja sesuai dengan cara kerja yang dialami otak kita, sehingga sistem ini dapat mengoptimalkan potensi yang dimiliki dan kapasitas dari otak manusia ([Menurut Caroline Edward 2009:64]) .[11]. 


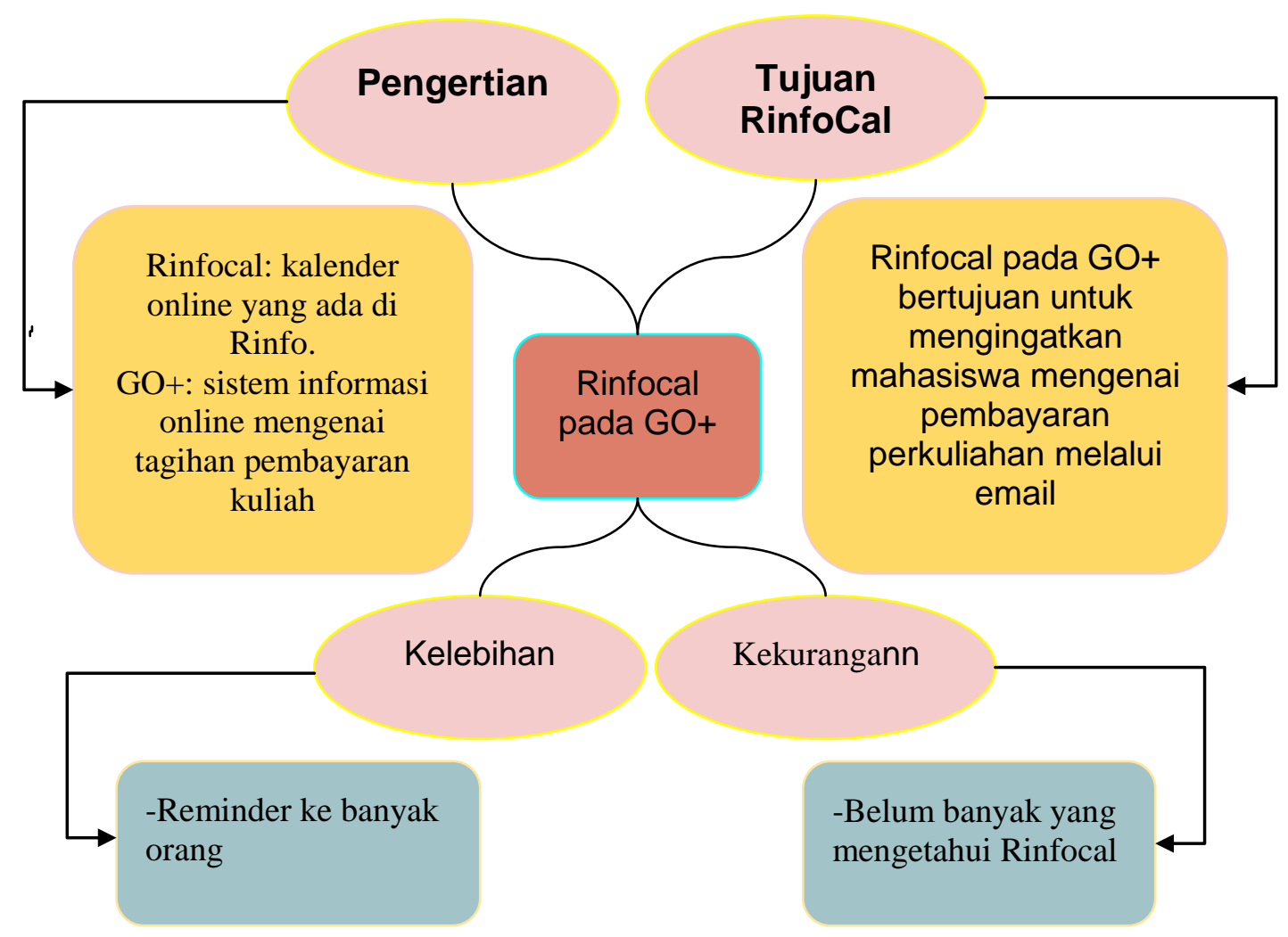

Gambar 4. Mind mapping penggunaan RinfoCal Pada GO+

Pada gambar mind maaping diatas dijelaskan apa itu RinfoCal dan GO+, kelebihan dan kekurangan RinfoCal dan GO+.

\section{Flowchart Rancangan Aplikasi}

Flowchart ialah metode yang biasa digunakan untuk menggambarkan tahap-tahap pemecahan masalah dengan cara menampilkan simbol-simbol tertentu yang dapat dengan mudah untuk dimengerti, mudah untuk dipakai , dan standar. ([Budi Sutedjo Dharma Oetomo: 2002;126]).

Setelah melakukan pengamatan dan meneliti permasalahan yang terjadi pada sistem yang sedang berjalan maka alur proses langkah program yang sedang berjalan ialah . [12] 


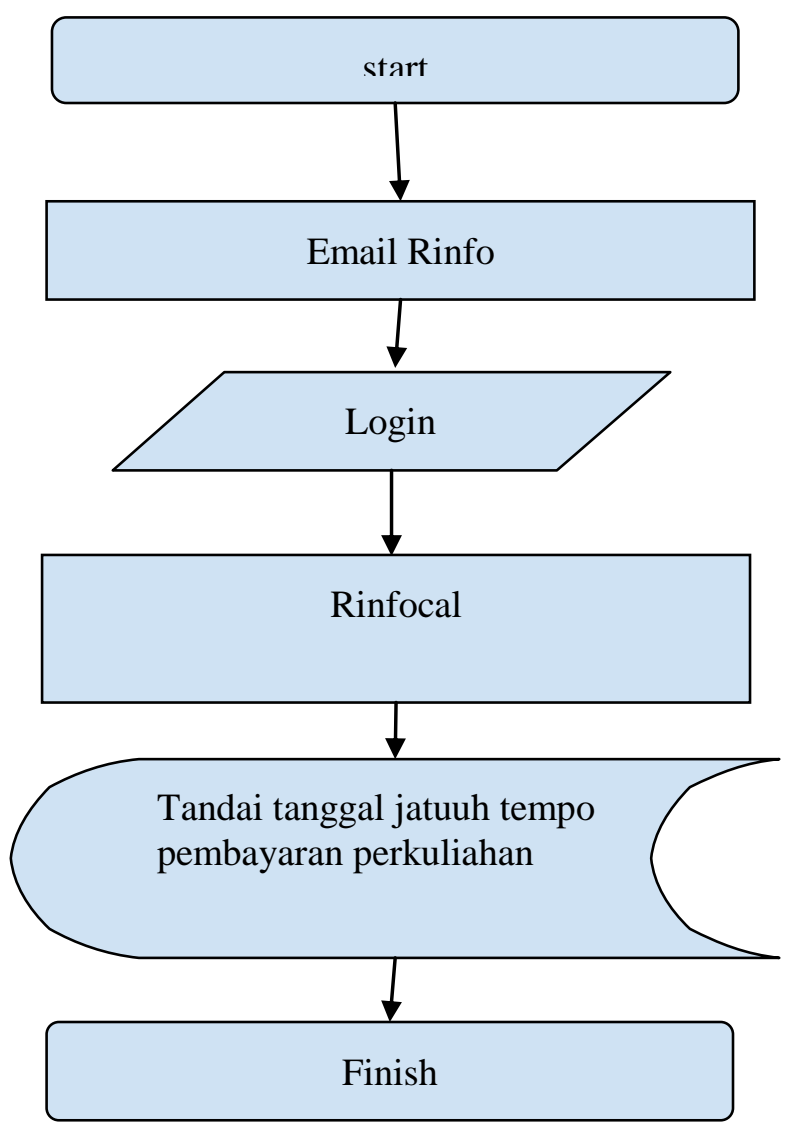

Gambar 5. Flowchart

Pada gambar flowchart diatas dapat dijelaskan bahwa langkah pertama yang perlu dilakukan mahasiswa ialah membuka Rinfo dan login dengan akun rinfo setelah itu pilih tools Rinfocal yang terdapat di Rinfo tandai tanggal batas waktu pembayaran setelah itu notifikasi rincian biaya berupa email akan dikirimkan langsung melalui rinfo tanpa harus membuka website dan mengunjungi kasir.

4. Prototype

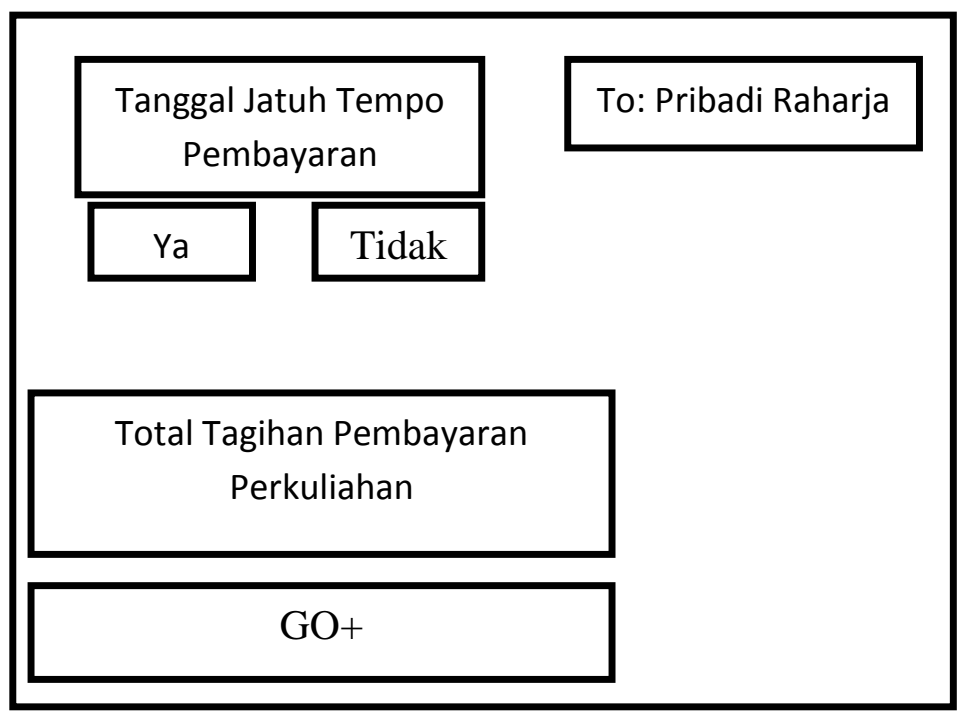

Gambar 6. Prototype 


\section{IMPLEMENTASI}

Sistem GO+ telah diterapkan oleh Perguruan Tinggi Raharja untuk mendukung pelaksanaan pembayaran perkuliahan. Selain itu Rinfocal juga telah diterapkan oleh perguruan tinggi raharja untuk mengingatkan kegiatan kampus kepada mahasiswa perguruan tinggi raharja.

1. Tampilan home GO+

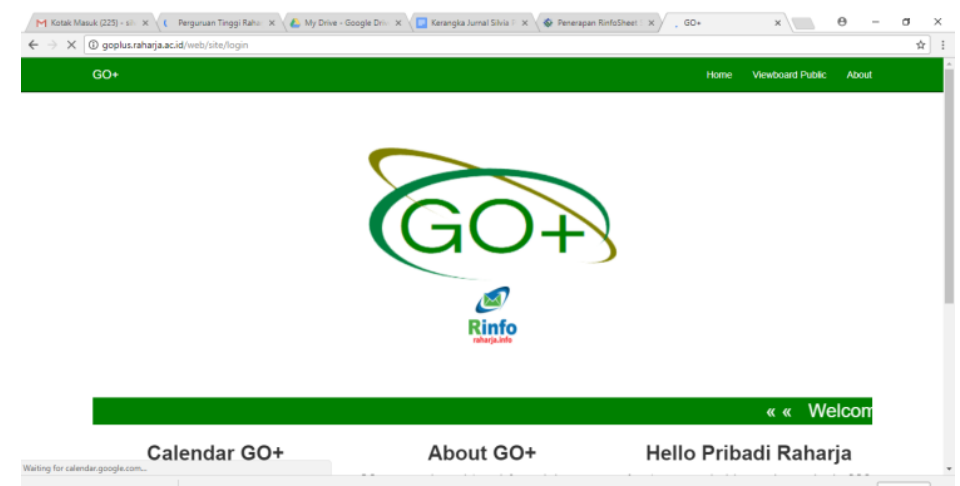

Gambar 7. Tampilan utama GO+

Mahasiswa dapat membuka alamat website www.goplus.raharja.ac.id untuk langsung mengetahui total tagihan biaya kuliah

2. Tampilan total tagihan biaya kuliah

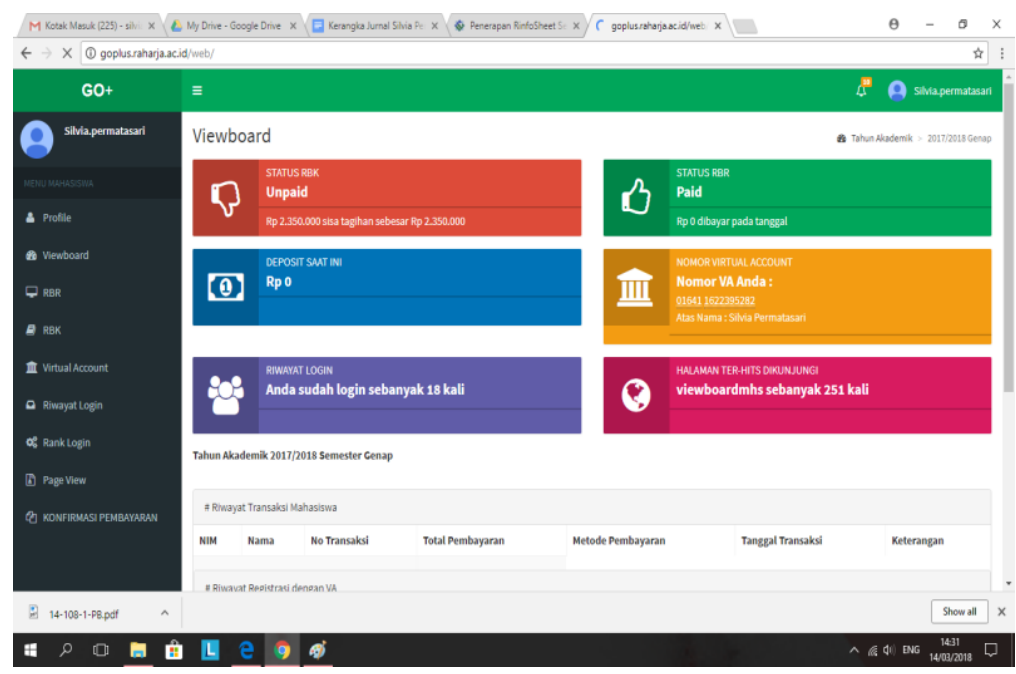

Gambar 8. Tampilan total tagiham biaya kuliah

Setelah melakukan login pada GO+ dengan akun rinfo pribadi raharja dapat mengetahui langsung total tagihan biaya perkuliahan yang harus dibayar dan mengetahui batas akhir pembayaran kuliah. 


\section{Login Rinfo}

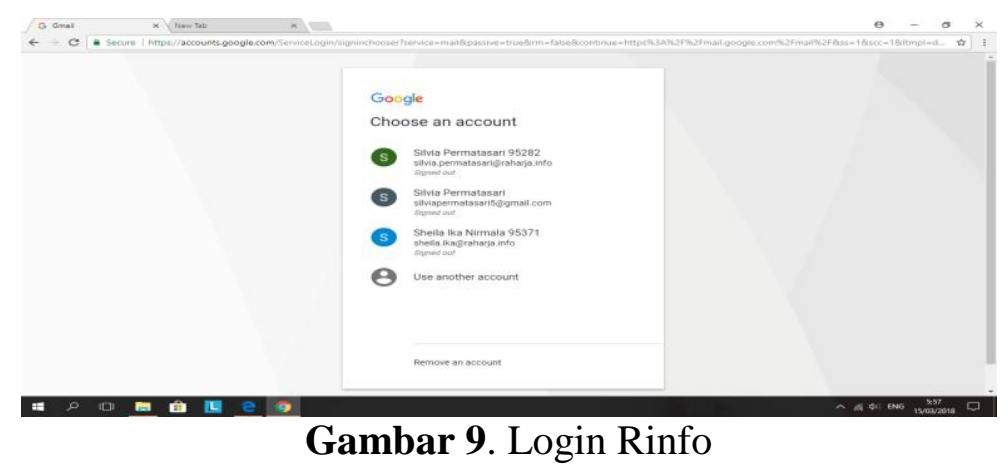

Gambar diatas menjelaskan bahwa staf bagian kasir dan mahasiswa harus Login terlebih dahulu dengan akun rinfo.

4. Tampilan Home Rinfo

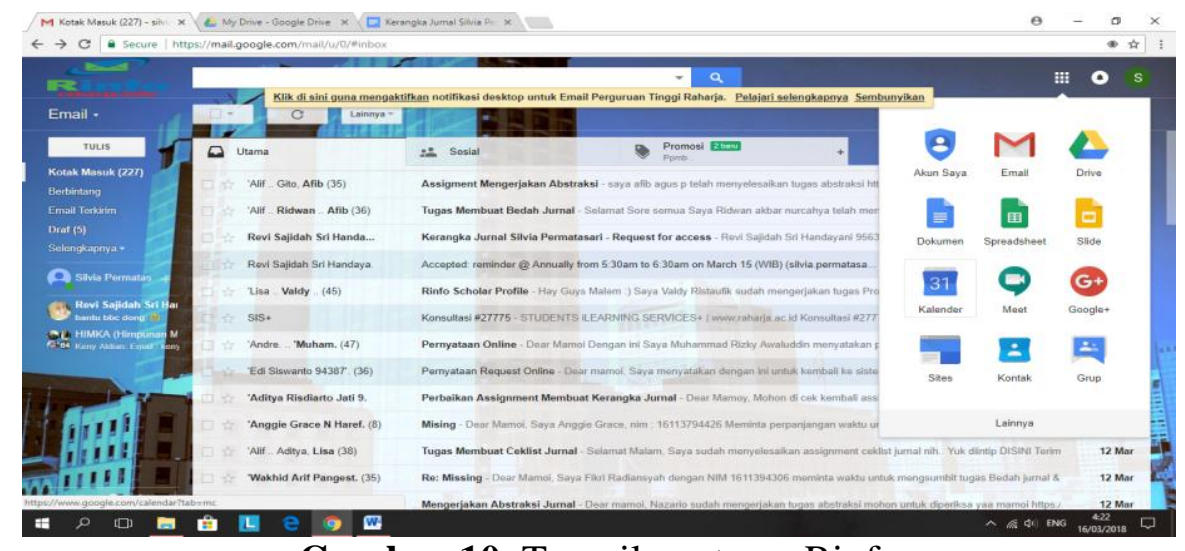

Gambar 10. Tampilan utama Rinfo

Setelah melakukan Login maka akan muncul tampilan utama Rinfo

5. Tampilan Rinfocal

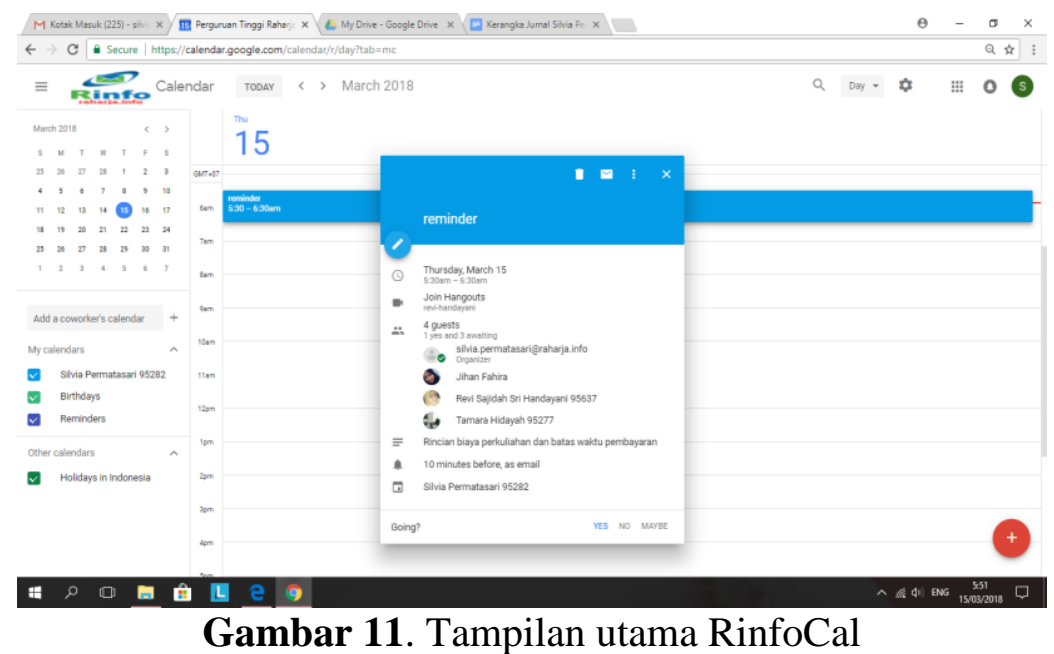

Setelah login staf bagian kasir akan menandai tanggal batas akhir pembayaran biaya kuliah di 
Rinfocal kepada pribadi raharja, setelah itu Rinfocal akan mengirimkan notifikasi berupa email website GO+ untuk mengetahui tagihan biaya kuliah dan batas akhir pembayaran pada mahasiswa. Selain itu mahasiswa juga bisa menandai sendiri tanggal untuk reminder pembayaran di RinfoCal.

6. Reminder yang akan diterima oleh mahasiswa

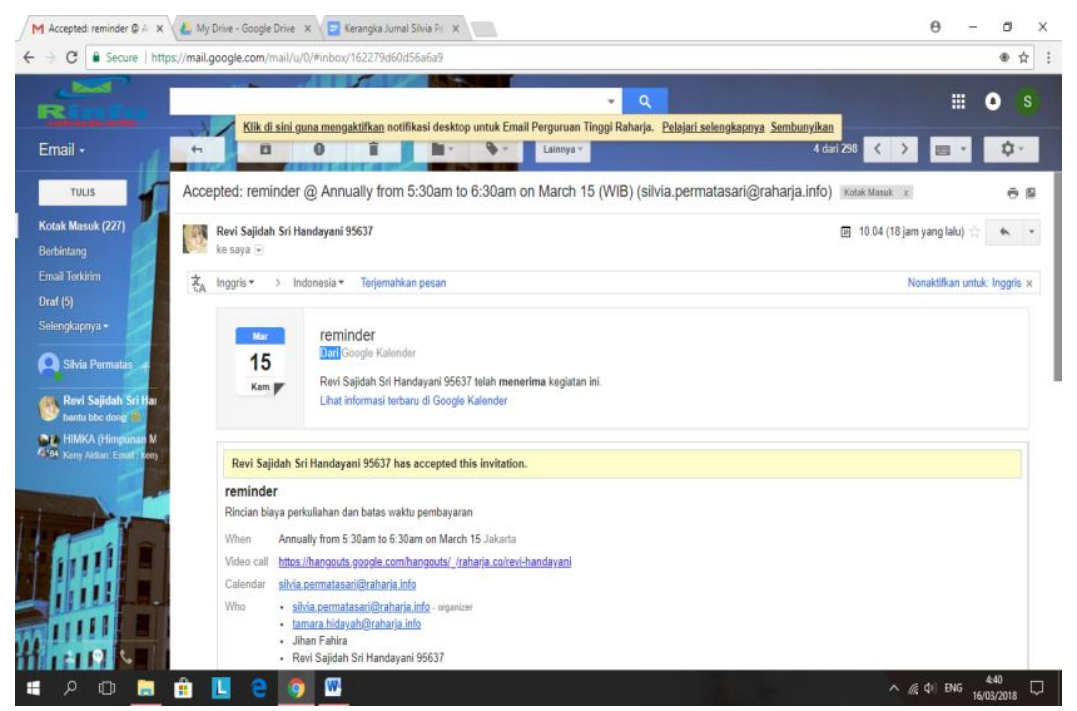

Gambar 12. Reminder yang diterima mahasiswa

Gambar diatas menggambarkan contoh notifikasi yang diterima oleh mahasiswa sebagai reminder pembayaran

\section{KELEBIHAN}

Dengan adanya pengembangan Rinfocal pada GO+ mahasiswa akan mendapatkan informasi secara cepat dan akurat. Terdapat 4 kelebihan dengan adanya pengembangan ini diantaranya ialah:

1. Memudahkan mahasiswa mendapatkan informasi tentang jatuh tempo waktu pembayaran perkuliahan dimanapun dan kapanpun

2. Memudahkan staf bagian kasir untuk menginformasikan kepada mahasiswa tentang jatuh tempo waktu pembayaran

3. Dengan adanya pengembangan ini kampus perguruan tinggi raharja tidak perlu membuat spanduk berisi informasi jatuh tempo pembayaran perkuliahan.

4. Memanfaatkan Rinfocal agar mahasiswa bisa menggunakan tools ini untuk mengingatkan mahasiswa tentang adanya kegiatan kampus seperti remider seminar, tugas, dan kegiatan akademik lainnya.

\section{KEKURANGAN}

Pengembangan ini tentu masih memiliki beberapa kekurangan diantaranya ialah terdapat 2 kekurangan yaitu:

1. Mahasiswa hanya bisa mengetahui tanggal jatuh tempo pembayaran.

2. Mahasiswa tidak bisa mengetahui secara langsung berapa total tagihan biaya perkuliahannya.

\section{KESIMPULAN}

Dengan demikian dapat disimpulkan. GO+ merupakan sistem online perguruan tinggi raharja yang berisi informasi mengenai biaya perkuliahan yamg dapat diakses online melalui 
sis+ dan bisa di akses langsung melalui web goplus.raharja.ac.id. Sedangkan RinfoCal sendiri ialah kalender online yang merupakan sebuah tools yang terdapat di Rinfo. Dengan adanya rinfocal pada GO+ sebagai reminder pembayaran diharapkan dapat membantu mahasiswa untuk mengingat batas waktu tanggal pembayaran tanpa datang ke kasir. Tentunya hal tersebut akan sangat efektif dalam hal waktu.

\section{SARAN}

Pengembangan sistem selanjutnya, saran yang dapat diberikan yaitu untuk mengembangkan $\mathrm{GO}+$ berbasis aplikasi agar mahasiswa dapat mengetahui informasi dengan lebih efektif dan lebih cepat sehingga mahaiswa tidak perlu mengecek email. Selain itu saran perkembangan selanjutnya notifikasi dapat dikirim melalui SMS sehingga mahasiswi dapat mendapatkan informasi dalam keadaan offline.

\section{DAFTAR PUSTAKA}

1) Tiara, Khanna, Tuti Nurhaeni, and Yeti Faradisa. "PENERAPAN GO+ BERBASIS WEB UNTUK MENINGKATKAN MUTU PELAYANAN LEMBAGA KEUANGAN MAHASISIWA." Technomedia Journal 1, no. 2 (2017): 90-105.

2) Yusup, Muhamad, Augury El Rayeb, and Sri Rahayu. "IMPLEMENTASI ARTIFICIAL INFORMATICS PADA SISTEM INFORMASI KALENDER AKADEMIK DALAM PENYEBARAN INFORMASI DI PERGURUAN TINGGI." CCIT Journal 4, no. 3 (2011): 221-236.

3) Rahardja, Untung, Khanna Tiara, and Ray Indra Taufik Wijaya. "Penerapan Rinfo Sebagai Media Pendukung Untuk Proses Pembelajaran Pada Perguruan Tinggi Raharja." Jurnal CCIT8, no. 1 (2014).

4) Aini, Qurotul, Rubin Hakita Irwin, and Eka Marjayanti. "Notifikasi Pembelajaran iLearning Melalui Media Aplikasi iDu dengan Menggunakan E-mail Rinfo." Technomedia Journal 1, no. 2 (2017): 1-12.

5) Handayani, Indri, Qurotul Aini, and Yessy Oktavyanti. "Penggunaan RinfoCal Sebagai Aplikasi Pengingat (Reminder) Kegiatan Akademik Pada Perguruan Tinggi." CCIT Journal 9, no. 1 (2015): 13-26.

6) Handayani, Indri, Qurotul Aini, and Yessy Oktavyanti. "Penggunaan RinfoCal Sebagai Aplikasi Pengingat (Reminder) Kegiatan Akademik Pada Perguruan Tinggi." CCIT Journal 9, no. 1 (2015): 13-26.

7) Azizah, Nur, and Andri Ansyah. "PERANCANGAN SISTEM INFORMASI MONITORING ANTRIAN PEMBAYARAN KULIAH PADA LKM PERGURUAN TINGGI RAHARJA." CCIT Journal 9, no. 1 (2015): 60-70.

8)Yusup, Muhamad, Untung Rahardja, and Susan Oktaviani. "GO+ Dalam Menunjang Int+ Untuk Pengelolaan Data Cmb Pada Perguruan Tinggi." CCIT Journal 8, no. 1 (2014): 65-

9)Rasdiana, Erlita, and Nursam Somantri. "Penerapan RinfoSheet Sebagai Media Penunjang Pembuatan Laporan Untuk Mahasiswa." Technomedia Journal 1, no. 1 (2016): 36-49.

10)Tiara, Khanna, and Tuti Nurhaeni. "Penerapan Viewboard GO+ Berbasis Yii Sebagai Media Monitoring Pembayaran Mahasiswa." Technomedia Journal 1, no. 1 (2016): 65-77.

11) Rahardja, Untung, Indri Handayani, and Rizki Afri Liani Firmansyah. "Penerapan SPB Online Menggunakan Rinfo Transformation Pada Bagian Pengadaan Perguruan Tinggi." CogITo Smart Journal 2, no. 1 (2016): 69-81. 